\title{
Alterations in Peripheral B Cell Subsets Correlate with the Disease Severity of Human Glaucoma
}

\author{
Ling $\mathrm{Yu}\left(\mathbb{D}^{1, *}\right.$ \\ Yang Chen ${ }^{2, *}$ \\ Xiang $\mathrm{Xu}^{2}$ \\ Qiwei Dong ${ }^{2,3}$ \\ Wenbo $\mathrm{Xiu}^{2}$ \\ Qinyuan Chen ${ }^{2}$ \\ Jinxia Wang ${ }^{2}$ \\ Chong $\mathrm{He}^{2,3}$ \\ Jian $\mathrm{Ye}^{\mathrm{l}}$ \\ Fang $\mathrm{Lu}^{2,3}$
}

'Department of Ophthalmology, Daping Hospital, Army Medical Center, Army Medical University, Chongqing, People's Republic of China; ${ }^{2}$ Clinical Immunology Translational Medicine Key Laboratory of Sichuan Province, Sichuan Provincial People's Hospital, University of Electronic Science and Technology of China, Chengdu, People's Republic of China; ${ }^{3}$ Medico-Engineering Cooperation on Applied Medicine Research Center, University of Electronic Science and Technology of China, Chengdu, People's Republic of China

*These authors contributed equally to this work

Correspondence: Fang Lu

Clinical Immunology Translational

Medicine Key Laboratory of Sichuan Province, Sichuan Provincial People's Hospital, University of Electronic Science and Technology of China, 32 The First

Ring Road West 2, Chengdu, Sichuan,

610072, People's Republic of China

$\mathrm{Tel} / \mathrm{Fax}+86-028-8739420 \mathrm{I}$

Email lufangfang@|26.com

Jian Ye

Department of Ophthalmology, Daping Hospital, Army Medical Center, Army Medical University, No. 10, Changjiang Branch, Daping, Yuzhong District, Chongqing, 400042, People's Republic of China

$\mathrm{Tel} / \mathrm{Fax}+86-023-688 \mathrm{I}$ I 229

Email yejian1979@I63.com
Background: Glaucoma is a group of retinal neurodegenerative diseases causing irreversible visual impairment. The pathogenesis of this disease is complicated. Studies have shown that the immune system is involved in the neurodegenerative process of glaucoma. There are continuous evidences that autoantibodies play a crucial role in the pathogenesis of glaucoma. However, focuses on B cells, the antibody-producing cells in glaucoma are surprisingly limited.

Methods: Fresh peripheral blood samples were collected from 44 glaucoma patients (38 with primary angle-closure glaucoma (PACG) and 6 with (primary open-angle glaucoma POAG)) and 36 age-matched healthy donors (HD). Density gradient centrifugation was performed to obtain peripheral blood mononuclear cells (PBMC). Flow cytometry was performed to determine B cell phenotypes. The severity of glaucoma was determined based on the mean deviation (MD) of visual field.

Results: In this study, we demonstrated that total B cells was significantly increased in glaucoma patients compared to HD. Next, we checked changes of different B cell subsets in glaucoma. Glaucoma patients were found to have a significant increase in the frequencies of antibody-secreting cells (ASC)/plasmablasts, naïve, and $\mathrm{CD} 19^{+} \mathrm{CD} 27^{-} \mathrm{IgD}^{-}$double negative (DN) subpopulations, but a decrease in the $\mathrm{CD} 27^{+} \mathrm{IgD}^{+}$unswitched memory compartment. Notably, we found that the increment of $\mathrm{CD} 27^{-} \mathrm{IgD}^{-} \mathrm{DN}$ B cells was significantly magnified according to the clinical severity.

Conclusion: We demonstrate, for the first time, that peripheral B cell subsets are altered and unveil the correlation of a newly identified pro-inflammatory $\mathrm{CD} 27^{-} \mathrm{IgD}^{-} \mathrm{DN}$ subset with clinical features of glaucoma, suggesting that these B cell subsets could serve as potential biomarkers to monitor the disease progression of glaucoma patients.

Keywords: glaucoma, $\mathrm{B}$ cells, $\mathrm{CD} 27^{-} \mathrm{IgD}^{-}$double negative $\mathrm{B}$ cells, retinal neurodegeneration

\section{Introduction}

Glaucoma is a group of neurodegenerative diseases with a complex pathogenesis, which mainly affects the retinal ganglion cells (RGC) and optic nerve (ON), leading to irreversible visual impairment. There are about 70 million glaucoma patients in the world, about half of them in Asia, while nearly 10 million glaucoma patients in China. $^{1,2}$

The pathogenesis of glaucoma is complicated and it is considered that high intraocular pressure (IOP) is the most important risk factor in the pathogenesis of glaucoma. IOP reduction surgery is still the most commonly used treatment for retinal damage of glaucoma, ${ }^{3-5}$ but patients with elevated IOP do not necessarily suffer from RGC/ON damage, while patients with normal or effectively controlled 
IOP might still have progressive neurodegenerative damage. Therefore, more and more studies begin to pay attention to other factors that might be related to retinal neurodegeneration besides IOP, in order to find novel therapeutic intervention. ${ }^{6,7}$ It has been implicated that there are other factors related to the pathogenesis of glaucoma, such as vascular factors, ${ }^{8}$ high myopia, ${ }^{9,10}$ oxidative stress, ${ }^{11}$ and immune responses. ${ }^{6,12}$

Increasing clinical and experimental studies have shown that an immunologic component is involved in the neurodegenerative process of glaucoma. ${ }^{7}$ Studies have shown that the proliferation and activation of microglial cells (MGC) in the retina of glaucomatous mice are upregulated, and the pharmacological intervention in the early stage of the disease is able to deactivate MGC, which is effective in reducing nerve injury. ${ }^{13}$ In addition to innate immunity, the role of antibodies, which belong to the adaptive arm of the immune system, in the pathogenesis of glaucoma has also attracted much attention. ${ }^{14,15}$ Two decades ago, Wax's team discovered that antibody against HSP60 was up-regulated in the serum of glaucoma patients and implicated that this antibody might be involved in the glaucomatous optic neuropathy process in an IOP-independent manner. ${ }^{16-18}$ Since then, different studies have revealed a variety of autoantibodies against retinal and ON antigens have been altered in sera and aqueous humour of glaucoma patients. ${ }^{19}$ For example, antibodies against $\mathrm{HSP} 70,{ }^{20} \alpha$-fodrin, ${ }^{21}$ myelin basic protein (MBP), ${ }^{22}$ or $\mathrm{HSP} 27^{23}$ are significantly up-regulated, while those against glial fibrillary acidic protein (GFAP) ${ }^{22}$ or vimentin ${ }^{20}$ are down-regulated. Amounts of studies have emphasized the importance of autoantibodies in the pathogenesis of glaucoma. In 1998, Wax and the team demonstrated, for the first time, that antibodies were accumulated in the retina of a patients with $\mathrm{NTG}^{24}$ and this was further verified by a following study showing RGC loss was accompanied by evident autoantibody deposits in 4 glaucomatous donor retinas. ${ }^{25}$ Studies on an experimental glaucoma animal model induced by specific antigen immunization revealed similar alterations of antibody profiles compared to those in human glaucoma. ${ }^{26-28}$ Of note, RGC and ON degeneration was observed to be often accompanied with antibody deposits and occur in the areas where the antibodies were accumulated. ${ }^{29-31}$ Besides pathogenic roles, some antibodies have been implicated to have neuroprotective potential. Several decreased antibodies in human glaucoma have been identified to be protective against stress factors, which have been implicated in the pathogenesis of glaucoma. ${ }^{11}$ For instance, in vitro preincubation of RGC-5 (a neuroretinal cell line) with antibody against the protein kinase inhibitor 14-3-3 or $\gamma$-synuclein evidently abrogates reactive oxygen species (ROS) generation induced by different stress factors and increases cell viability. ${ }^{32,33}$ Although great progresses have been made in the understanding of autoantibodies in glaucoma, focuses on B cells, the antibody-producing cells, in glaucoma are surprisingly limited. Previous studies have shown that B cell infiltration in the retina of glaucoma patients, but no reports have explored the B cell subset alteration in the peripheral blood of glaucoma patients.

In this study, we enrolled 44 patients with glaucoma and 36 age-matched healthy donors (HD), collected their peripheral blood, and performed flow cytometry to determine the alterations of total B cells and their subsets in the peripheral blood of glaucoma patients. We found that total B cells, antibody-secreting cells (ASC)/plasmablasts, naïve, and $\mathrm{CD}_{1} 9^{+} \mathrm{CD} 27^{-} \mathrm{IgD}^{-}$double negative (DN) subpopulations were significantly up-regulated, while the unswitched memory compartment was remarkably downregulated. Notably, we found that the $\mathrm{CD}_{2} 7^{-} \mathrm{IgD}^{-} \mathrm{DN}$ subset was positively associated with the clinical severity of glaucoma. We here, for the first time, demonstrate that peripheral B cell subsets are altered and unveils the correlation of a newly identified pro-inflammatory $\mathrm{CD} 27^{-} \mathrm{IgD}^{-}$ DN subset with clinical severity of glaucoma, suggesting that these B cell subsets could serve as potential biomarkers to monitor the disease progression of glaucoma patients.

\section{Materials and Methods}

\section{Subjects}

Our study was conducted in accordance with the Declaration of Helsinki and approved by the Institutional Review Board for Clinical Research of the Daping Hospital (No. 202192), and Sichuan Provincial People's Hospital (No. 201968). All subjects were well informed about the study and potential risk and signed an informed consent before participation. To investigate the subset distribution and functional changes of B cells in human glaucoma, we enrolled 44 patients with glaucoma (38 with primary angle-closure glaucoma (PACG) and 6 with (primary open-angle glaucoma POAG)) and 36 agematched healthy donors (HD) from the Department of Ophthalmology, Daping Hospital (Chongqing, China). 
All subjects (glaucoma patients and HD) underwent the standard workup for glaucoma, including medical history, physical and ophthalmologic examination, visual field tests and optical coherence tomography (OCT). Glaucoma was diagnosed according to the combination of age, family history, glaucomatous clinical manifestation, IOP elevation, cup to disk ratio, visual field loss and the thickness of RNFL. The exclusion criteria of glaucoma patients or HD who had no clinical evidence of glaucoma or a family history of glaucoma in this study: subjects with a history of other ocular diseases (such as uveitis, aged macular degeneration, cataracts, high myopia and retinitis pigmentosa), hypertension, diabetes, cardiovascular diseases, systemic autoimmune diseases or cancers, or subjects taking any systemic medications affecting the immune system were excluded. The severity of glaucoma was determined based on the mean deviation (MD) of visual field: mild indicates visual field MD of greater than $-6 \mathrm{~dB}$; moderate, $-12 \mathrm{~dB}$ to $-6 \mathrm{~dB}$; and severe, no greater than $-12 \mathrm{~dB}^{34}$ The demographics of subjects enrolled in this study were shown in Table 1.

\section{Blood Sample Collection and Flow Cytometry}

Peripheral blood $(10 \mathrm{~mL})$ was collected on the day when patients were hospitalized for surgery (before surgery) using sodium heparin-anticoagulated Vacutainer CPT tubes (BD Biosciences, San Diego, CA, USA). At the time of blood sampling, no subjects had an acute infection or were taking any medication known to influence immune function. Blood samples were immediately processed within 2 hours to obtain peripheral blood mononuclear cells (PBMC) as described previously. ${ }^{35}$ Briefly, fresh blood samples were diluted 1:1 with $\mathrm{Ca}^{2+} / \mathrm{Mg}^{2+}$ free phosphate buffered saline (PBS) and then overlaid onto Ficoll (Ficoll Paque; GE Healthcare, twice the volume of PBS-blood) in a $50 \mathrm{~mL}$ centrifuge tube. Density gradient centrifugation was then performed at room temperature for 20 minutes at $2000 \mathrm{rpm}$ and the cloudy interface between ficoll and serum was collected to obtain PBMC. After being washed twice in cold Stain Buffer containing BSA (BD Biosciences, RRID: AB_2869007), freshly isolated PBMC were used for flow cytometric staining. PBMC $\left(10^{6}\right.$ cells for each flow cytometric test) were divided into 4 tests: 3 replicates for B cell phenotype (the mean value of 3 replicates was shown in each figure) and 1 for corresponding isotype staining. To determine B cell phenotype, PBMC were stained for viability (LIVE/DEAD ${ }^{\mathrm{TM}}$ Fixable
Near-IR Dead Cell Stain Kit, Invitrogen, Thermo Fisher Scientific, USA) and fluorochrome-conjugated antibodies (all antibodies and their matched isotype antibodies were purchased from BioLegend, San Diego, CA, USA) against CD19 (AB_314245), CD27 (AB_314297), CD38 (AB_2561901), IgD (AB_2561386), CD24 (AB_10962689) for 30 minutes. Matched isotype antibodies were used simultaneously to exclude non-specific antibody binding and spectral overlap. After washed by Stain Buffer, 1\% paraformaldehyde was used to resuspend cells. Flow cytometric data were acquired using a FACS Canto II flow cytometer (BD Biosciences) and analyzed using FlowJo software (Tree Star, Ashland, OR, USA).

\section{Statistical Analysis}

The statistical analysis was performed by using a Prism software (GraphPad Software, San Diego, California, USA). Data are presented as mean \pm SD. Unpaired Student's $t$-test (two-tailed) was performed to determine the statistic difference between 2 groups and $p<0.05$ was considered statistically significant. When the number of groups $=3$, one-way analysis of variance (ANOVA) was applied. For the comparation between different groups, Bonferroni Correction was performed to adjust the alpha value and $\mathrm{p}<0.015$ was considered statistically significant.

\section{Results \\ Total B Cells and Antibody-Secreting Cells are Increased in the Peripheral Blood of Patients with Glaucoma}

To determine the phenotypic changes of peripheral B cells in glaucoma patients. We performed flow cytometry to determine the subset distribution and functional changes of B cells (Figure 1). ${ }^{36}$ First of all, we analyzed whether the amount of total B cells was altered. Flow cytometric staining for CD19 (gated on total live PBMC), the lineage marker of B cells, showed a significant increase of CD19 ${ }^{+}$ cells (total B cells) (Figure 2A and B). After antigen stimulation, B cells become activated B cells with the help of antigen-presenting cells and $\mathrm{T}$ helper cells, and then differentiate into plasmablasts, which are further differentiated and proliferated into antibody-secreting cells (ASC) (also called plasma cells). ASC are able to synthesize and secrete various kinds of antibodies. As showed in Figure $2 \mathrm{C}$ and $\mathrm{D}, \mathrm{CD} 19^{+} \mathrm{CD} 27^{+} \mathrm{CD} 38^{+}$cells were identified as ASC/plasmablasts and glaucoma patients were 
Table I Demographics of the Study Groups and Clinical Characteristics of Glaucoma

\begin{tabular}{|c|c|c|c|}
\hline Variables & Glaucoma & Healthy Donors & $P$ value \\
\hline$n$ & 44 & 36 & - \\
\hline Age (year) & $52 \pm 7$ & $50 \pm 8$ & $0.82^{\mathrm{a}}$ \\
\hline Age distribution & & & $0.9783^{b}$ \\
\hline$\leq 40$ & $3(6.8 \%)$ & $2(5.6 \%)$ & \\
\hline $4 I-49$ & 12 (27.3\%) & II (30.6\%) & \\
\hline $50-59$ & 27 (6I.4\%) & $21(58.3 \%)$ & \\
\hline$\geq 60$ & $2(4.5 \%)$ & $2(5.6 \%)$ & \\
\hline Sex, female & 21 (47.7\%) & I7 (47.2\%) & $>0.99^{c}$ \\
\hline \multicolumn{4}{|l|}{ Clinical type } \\
\hline PACG/POAG & $38 / 6$ & - & - \\
\hline IOP, mean & $29.22 \pm 1.81$ & $16.45 \pm 0.21$ & $<0.001^{d}$ \\
\hline \multicolumn{4}{|l|}{ Duration $^{\mathrm{e}}$} \\
\hline Group I (day) & $12.83 \pm 5.15$ & - & - \\
\hline Group 2 (month) & $5.29 \pm 2.56$ & - & - \\
\hline Group 3 (year) & $4.14 \pm 2.88$ & - & - \\
\hline \multicolumn{4}{|l|}{ Glaucoma severity } \\
\hline Mild & 17 (38.6\%) & - & - \\
\hline Moderate & 8 (I8.2\%) & - & - \\
\hline Severe & 19 (43.2\%) & - & - \\
\hline
\end{tabular}

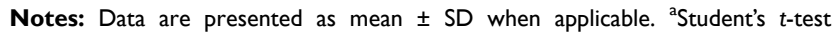
(unpaired, two-tailed). ${ }^{b}$ Chi-square test. ${ }^{\mathrm{c}}$ Chi-square test. ${ }^{\mathrm{d}}$ Student's $t$-test (unpaired, two-tailed). ${ }^{\mathrm{e}}$ All patients enrolled in this study were divided into 3 groups based on their disease duration: I, duration of shorter than I month $(n=6) ; 2, I-12$ months $(n=17)$; 3, longer than I year $(n=21)$.

Abbreviations: PACG, primary angle-closure glaucoma; POAG, primary openangle glaucoma; IOP, intraocular pressure.

found to have a significant increase in the frequency and absolute number of this subset compared to HD.

\section{Peripheral B Cell Subsets are Altered in Patients with Glaucoma}

Using our approach, we segregated non-ASC/plasmablasts $\mathrm{B}$ cells into 4 classical subsets in the peripheral circulation based on $\mathrm{CD} 27$ and $\mathrm{IgD}$ expression: $\mathrm{CD} 19^{+} \mathrm{CD} 27^{-} \mathrm{IgD}^{+}$ naïve $\mathrm{B}$ cells, $\mathrm{CD} 19^{+} \mathrm{CD} 27^{+} \mathrm{IgD}^{+}$unswitched memory $\mathrm{B}$ cells (also called IgM memory B cells), $\mathrm{CD} 19^{+} \mathrm{CD} 27^{+}$ $\mathrm{IgD}^{-}$classical switched memory $\mathrm{B}$ cells, and $\mathrm{CD} 19^{+}$ $\mathrm{CD} 27^{-} \mathrm{IgD}^{-}$double negative (DN) B cells (also called late memory B cells) (Figure 1). ${ }^{37}$ We first looked at the naïve compartment and found a slight but significant increase in glaucoma patients compared to HD (Figure 3A and B). Moreover, naïve population could be additionally separated by CD24 and CD38 expression subdivided into $\mathrm{CD} 24^{+} \mathrm{CD} 38^{+}$transitional cells, CD24
$\mathrm{CD} 38^{+}$mature cells, and a non-classic $\mathrm{CD} 24^{+} \mathrm{CD} 38^{-/ \text {low }}$ cells (Figure 1). We observed a significant increase in the transitional (Figure $3 \mathrm{C}$ and $\mathrm{D}$ ) and $\mathrm{CD} 24^{+} \mathrm{CD} 38^{-/ \text {low }}$ (Figure $3 \mathrm{G}$ and $\mathrm{H}$ ) fraction in glaucoma patients compared to HD. Although no significant changes were found in the frequency of the mature fraction (Figure 3E), the absolute number was markedly up-regulated (Figure 3F). Next, the memory compartments in both glaucoma patients and HD were checked. The unswitched memory subset was significantly reduced in the frequency (Figure 4A and B), but the absolute number of switched memory subset was enlarged in glaucoma patients compared with HD (Figure $4 \mathrm{C}$ and D). In addition, we observed that both frequency and absolute number of $\mathrm{CD} 27^{-} \mathrm{IgD}^{-} \mathrm{DN}$ $\mathrm{B}$ cells were evidently increased in glaucoma compared to those in HD (Figure 4E and F).

\section{Altered Peripheral B Cell Subsets are Associated with the Clinical Severity of Glaucoma}

Next, we aimed to investigate whether altered B cell subsets were associated with the clinical severity of glaucoma. We divided glaucoma patients into 3 categories based on visual field defects as described above. No significant differences in the total $\mathrm{B}$ cells and ASC/plasmablasts were observed among glaucoma patients with different severity (Supplementary Figure 1A and B). When B cell subsets were checked, we found that the frequency of $\mathrm{CD}^{-} 7^{-} \mathrm{IgD}^{-} \mathrm{DN}$ subset was significantly higher in severe cases than that in mild cases (Figure 5A), though the increase in their absolute number was insignificant as the disease severity worsened. The reduction of the unswitched memory B cells was significantly magnified according to the clinical severity (Figure $5 \mathrm{C}$ and $\mathrm{D}$ ). No remarkable changes were detected of the switched memory, naïve, mature, transitional and $\mathrm{CD} 24^{+} \mathrm{CD} 38^{-/ \text {low }}$ subsets among these 3 clinical categories of patients (Supplementary Figure 1C-G). Of note, we did not find any evident alterations of peripheral $\mathrm{B}$ cell subsets among patients with different disease duration (Supplementary Figure 2), or between those with different clinical subtypes (Supplementary Table 1) in the current study.

\section{Discussion}

In the current study, we investigated the alterations of B cell subsets in the peripheral blood of patients with glaucoma. To our best knowledge, this is the first report 
to demonstrate B cell subset alterations in human glaucoma. Our findings in glaucoma patients revealed that: 1) The number of total B cells were increased, indicative of an excessive $\mathrm{B}$ cell-mediated immune response in the disease. 2) ASC/plasmablasts were also up-regulated, which suggested that antibody secretion might be exaggerated. 3) Naïve B cells showed a slight but significant increase, indicating that $B$ cell generation might be enhanced. Additionally, a significant increase was observed in the transitional $\left(\mathrm{CD} 24^{+} \mathrm{CD} 38^{+}\right)$fraction. It has been demonstrated that inflammatory context facilitates the expansion of the $\mathrm{CD} 24^{+} \mathrm{CD} 38^{+}$transitional compartment in various autoimmune or infectious disorders. $^{38-40}$ Although this compartment is typically considered as "naïve", their capacity of differentiating into ASC has been reported. ${ }^{41}$ We here speculate that this transitional population might be associated with ASC differentiation and antibody production, and contribute to the glaucoma pathogenesis, but further investigation is required. 4) As for memory B cells, a decrease in the unswitched memory subset and an increase in the switched memory subset were found in glaucoma patients, suggestive of a possibility that pre-existing memory B cells might be re-activated and differentiate into atypical late memory $\mathrm{B}$ cells $\left(\mathrm{CD} 27^{-} \mathrm{IgD}^{-} \mathrm{DN}\right.$ subset, which was found to be enlarged in the disease) or effector cells, such as ASC/plasmablasts. ${ }^{42-44}$ 5) The amount of $\mathrm{CD}^{2} 7^{-} \mathrm{IgD}^{-} \mathrm{DN}$ subset was positively associated with the clinical severity of glaucoma, prompting us to speculate their potential to serve as biomarkers to monitor the disease progression. Interestingly, we did not find any significant alterations among groups when all enrolled patients were divided into 3 groups based on disease duration (Supplementary Figure 2) or into 2 groups based on disease subtype (Supplementary Table 1). We do realize that there are limitations in our current study, such as the limited sample size and failure to examine B cell subsets in retina biopsies of glaucoma patients, which are urgently needed to be addressed in future research.

Evidences suggest that neuroinflammation play a critical role in the pathogenesis of glaucoma. ${ }^{12}$ Unlike non-neural tissues, the retina is protected by the bloodretina barrier $(\mathrm{BRB})$ from the disturbance from peripheral immune cells, and exhibits an "immune privilege" nature. However, several recent studies by different groups have provided compelling evidence that peripheral leukocytes might be involved in the pathogenesis of glaucoma.
Studies have found that DBA/2J mice (which have spontaneous glaucoma) are largely protected from glaucomatous retinal degeneration after peripheral monocytes being removed by radiation, suggesting that the occurrence and development of glaucoma might require the participation of retinal innate immunity and peripheral immune cells. ${ }^{45}$ Adoptive transfer of lymphocytes from glaucoma mice induces glaucomatous RGC loss in recipient mice. ${ }^{15}$ Deficiency in $\mathrm{T}$ and $\mathrm{B}$ cells alleviates IOP elevationinduced RGC loss in mice. ${ }^{46}$ Therefore, increasing attention has been paid to the profile and role of peripheral lymphocytes. Recent studies have shown that peripheral $\mathrm{T}$ cell subsets are altered in glaucoma. The frequency of regulatory T cells (Treg) was decreased within the entire $\mathrm{CD}^{+}$or $\mathrm{CD}^{+}$population in glaucoma. ${ }^{47}$ Circulating IL-17Aproducing $\mathrm{CD}^{+} \mathrm{T}$ cell (known as Th17) frequency was found to be increased in patients with glaucoma. ${ }^{47}$ Besides T cells, B cells are one of the two arms of adaptive immunity, which are derived from bone marrow pluripotent stem cells. They play a role in the humoral immune components of the adaptive immune system by secreting antibodies. Although much effort has been made to elucidate the role of antibodies in glaucoma, the role of B cells themselves in the disease remains unknown. In fact, some studies have paid attention to B cells in ocular diseases. For example, upregulated levels of IgA and plasmablasts were observed in the peripheral blood of patients with age-related macular degeneration. ${ }^{48}$ Moreover, plasma cell infiltration has been found in the iris of children with ana-positive anterior uveitis, ${ }^{49}$ and regulatory $B$ cells play an immunosuppressive role in uveitis in an IL-10/IL-35 dependent manner. ${ }^{50}$ Additionally, it has even been considered to apply B cell depletion therapy (anti-CD20 monoclonal antibody, Rituximab) in uveitis. ${ }^{51,52}$ As for glaucoma, no reports, to our knowledge, have explored the peripheral B cell subset alterations. Our findings reveal that peripheral B cell subset are altered in glaucoma patients, but these data also raise several follow-up questions, such as how these alterations occur, are they the etiological factors or just the consequences of the disease progression, whether and how B cells contribute to the pathogenesis of glaucoma, and functions of different $B$ cell subsets in the disease. Previous studies by other groups have shown B cell infiltration in the retina of glaucoma patients, ${ }^{24,25}$ and that mice deficient in B cells display reduced RGC axon loss in the prolonged phase than wild-type controls. ${ }^{46}$ These evidences suggest a role of B cells in the development of glaucoma. Based on these observations in this study, we have already 

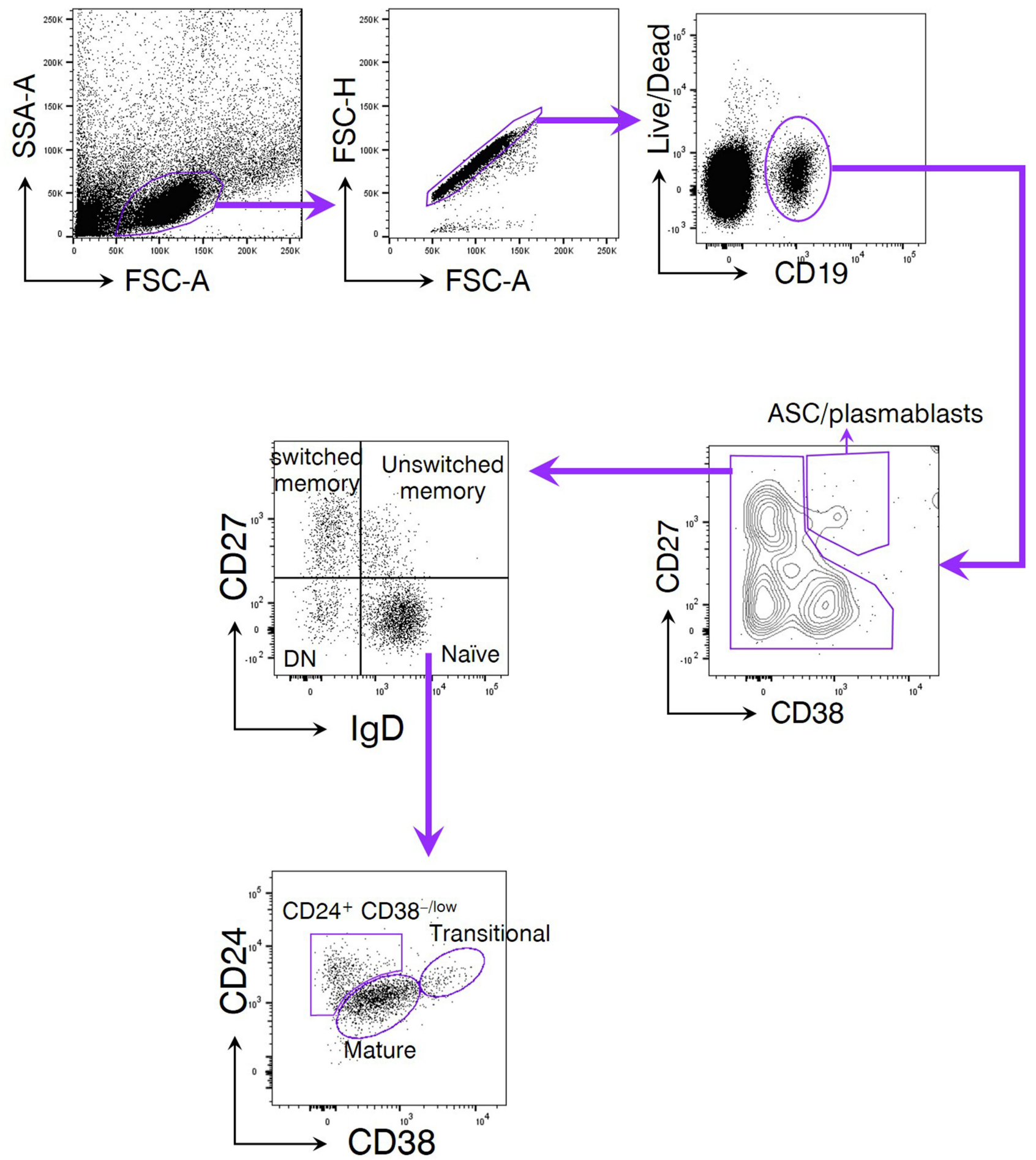

Figure I The gating strategy of peripheral blood B cell subsets. Peripheral blood mononuclear cells (PBMC) were isolated from subjects enrolled in the current study. A LIVE/DEAD TM Fixable Near-IR Dead Cell Stain Kit was used to determine the viability of PBMC. CDI9 was used as the lineage marker of total B cells. CD27 and CD38 were coupled to discriminate antibody-secreting cells (ASC)/plasmablasts due to their high expression of both markers. Non-ASC/plasmablasts B cells were segregated into 4 classical subsets based on $C D 27$ and $\operatorname{lgD}$ expression: $\mathrm{CD} 19^{+} \mathrm{CD} 27^{-} \lg \mathrm{D}^{+}$naïve $\mathrm{B}$ cells, $\mathrm{CD} 19^{+} \mathrm{CD} 27^{+} \lg \mathrm{D}^{+}$unswitched memory $\mathrm{B}$ cells (also called $\operatorname{lgM}$ memory $\mathrm{B}$ cells), $\mathrm{CD} 19^{+} \mathrm{CD} 27^{+} \mathrm{IgD}$ classical switched memory B cells, and $\mathrm{CD} 19^{+} \mathrm{CD} 27^{-} \mathrm{IgD}{ }^{-}$double negative (DN) B cells (also called late memory $\mathrm{B}$ cells). Among them, the naïve fraction could be additionally separated by CD24 and CD38 expression subdivided into $C D 24^{+} \mathrm{CD} 38^{+}$transitional cells, $\mathrm{CD} 24^{-} \mathrm{CD} 38^{+}$mature cells, and a non-classic CD $24^{+}$CD $38^{\text {-llow }}$ cells. 

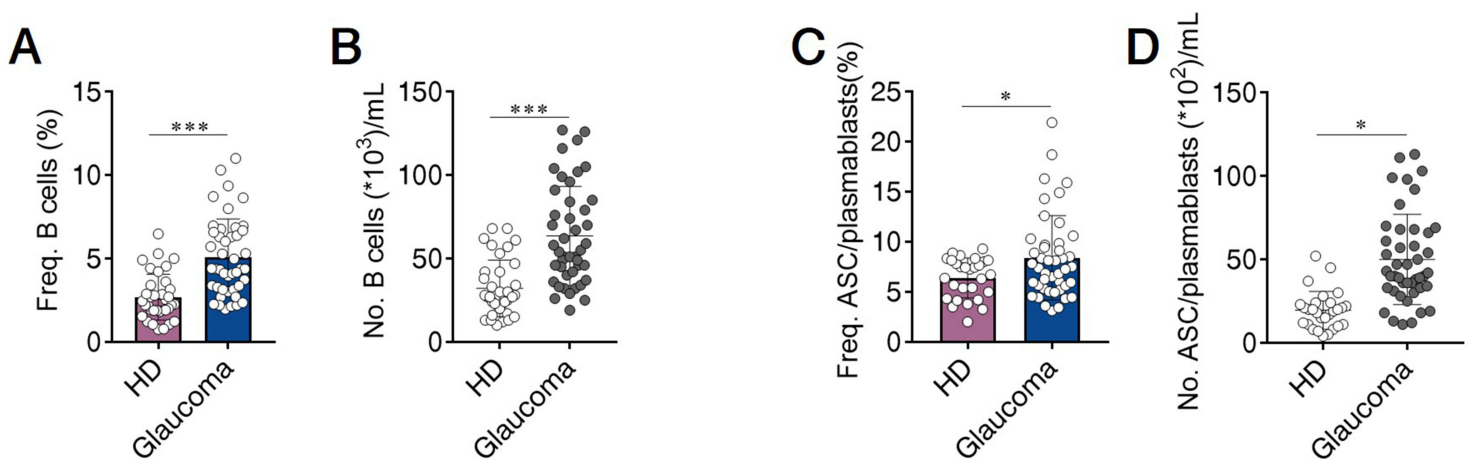

Figure 2 Total B cells and antibody-secreting cells (ASC)/plasmablasts are increased in the peripheral blood of patients with glaucoma. Peripheral blood mononuclear cells (PBMC) were isolated from patients with glaucoma $(n=44)$ and healthy donors $(H D, n=36)$. Total $B$ cells and ASC/plasmablasts were identified as described in Figure I. The frequency (Freq.) and absolute number (No.) of ( $\mathbf{A}$ and $\mathbf{B}$ ) total B cells and (C and $\mathbf{D})$ ASC/plasmablasts in glaucoma patients and HD were shown. ${ }^{*}<<0.05$, *** $<<0.00 \mathrm{I}$. Statistical comparisons were performed using unpaired Student's $t$-test (two-tailed). The data are represented as means \pm SD.
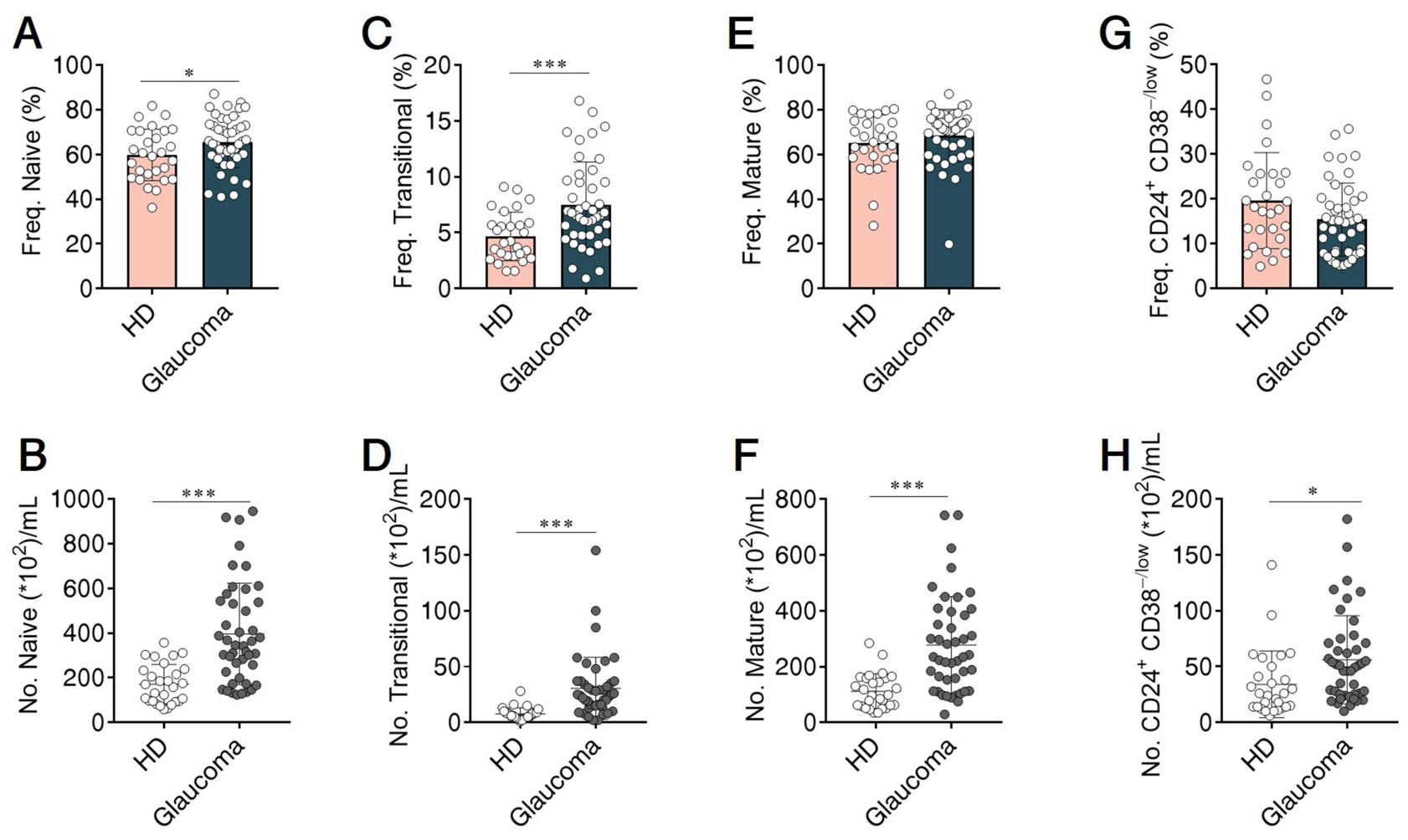

Figure 3 Altered naïv B cell compartments in patients with glaucoma. PBMC were isolated and naïve B cell compartments were gated as in Figures I and 2. The frequency and absolute number of $(\mathbf{A}$ and $\mathbf{B})$ total naïve $\mathbf{B}$ cells, and $(\mathbf{C}$ and $\mathbf{D})$ transitional, $(\mathbf{E}$ and $\mathbf{F})$ mature, $(\mathbf{G}$ and $\mathbf{H}) \mathrm{CD}_{2} 4^{+} \mathrm{CD} 38^{-/ l o w}$ subpopulations in glaucoma patients and HD were shown. ${ }^{*} p<0.05,{ }^{* * *} p<0.00$ I. Statistical comparisons were performed using unpaired Student's $t$-test (two-tailed). The data are represented as means \pm SD.

established IOP elevation-induced glaucoma mouse model and also find that the number of $\mathrm{B}$ cells is changed in the spleen, peripheral blood, and bone marrow (data not shown). Furthermore, we observe an altered chemokine profile on peripheral B cells in glaucoma mice (data not shown). Since chemokines play a crucial role in leukocyte migration and have been important targets for developing novel therapeutics in certain autoimmune diseases, ${ }^{53-55}$ our ongoing experiments point to several exciting directions for future research and night provide useful ideas for searching therapeutic targets in glaucoma, especially for which could be targeted by drugs that have already been applied in other clinical settings.

B cells are divided into several subpopulations according to their surface markers and often divided into four subgroups by using IgD and CD27. ${ }^{37} \mathrm{CD} 27$, one member of the TNF-R superfamily, is a universal surface marker of memory B cells. ${ }^{56,57}$ The expression of IgD, primarily expressed 

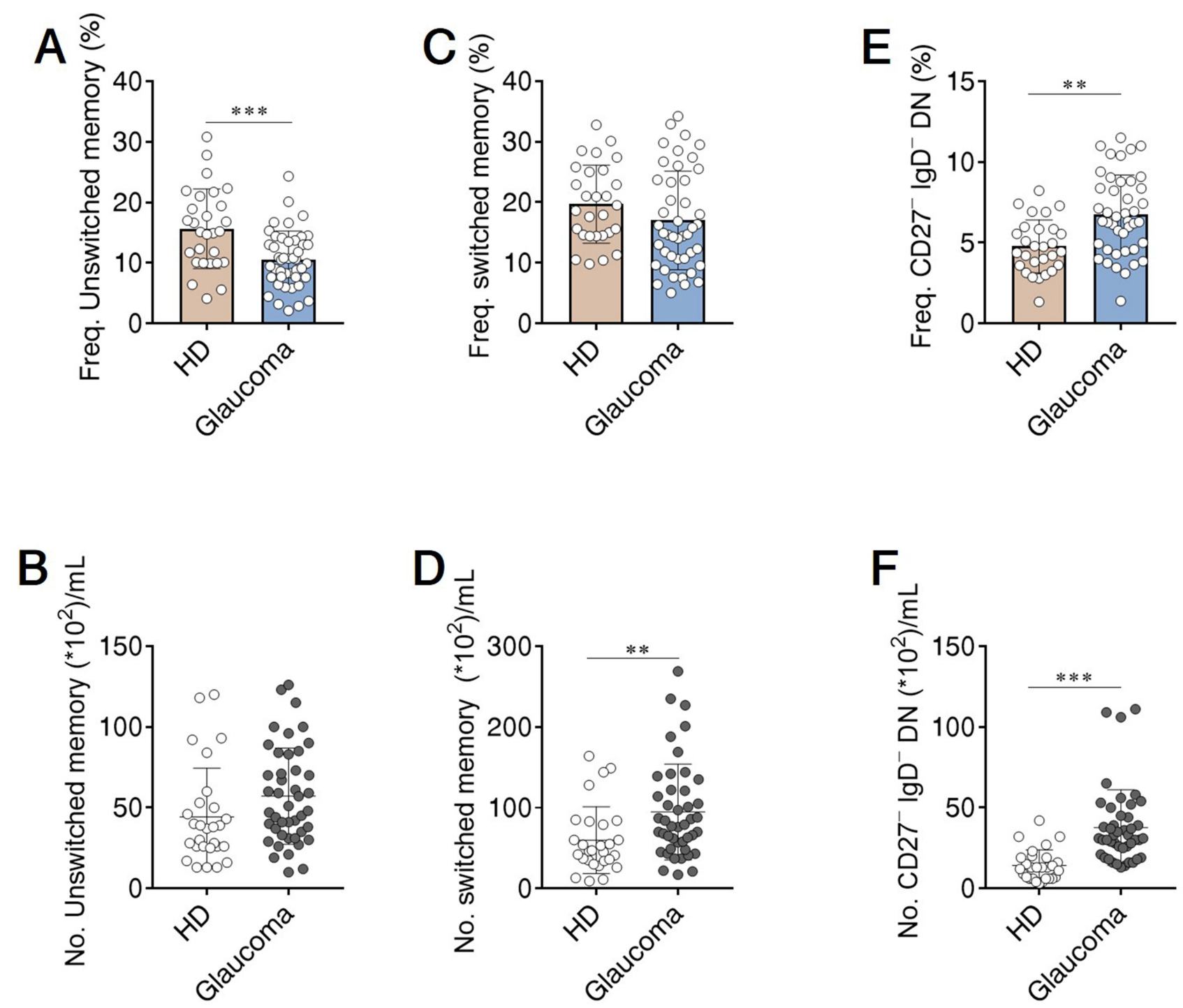

Figure 4 Memory B cell subsets were changed in patients with glaucoma. PBMC were isolated and memory B cell compartments were gated as in Figures I and 2. The frequency and absolute number of ( $\mathbf{A}$ and $\mathbf{B})$ unswitched memory, ( $\mathbf{C}$ and $\mathbf{D})$ switched memory, and (E and $\mathbf{F}) \mathrm{CD}_{2} 7^{-} \mathrm{IgD}{ }^{-} \mathrm{DN}$ subsets in glaucoma patients and HD were shown. ${ }^{* *} p<0.01, * * * p<0.001$. Statistical comparisons were performed using unpaired Student's $t$-test (two-tailed). The data are represented as means \pm SD.

by naïve B cells, is decreased when B cells have undergone isotype switch. Due to the absence of CD27, DN and naïve B cells were previously indistinguishable. On the other hand, the low expression of IgD indicates that DN B cells might be activated after antigen stimulation. ${ }^{58,59}$ So paradoxically, DN B cells, unlike the other three subgroups, have been poorly understood for decades. However, studies on this subset have been increasing in the last few years, providing evidences to improve our knowledge on their functions in immune responses. DN B cells are now widely accepted as a novel subset of memory rather than naïve $B$ cells. Under normal physiological conditions, DN B cells can be found in the frequency of approximately $5 \%$ of all peripheral blood B cells and the rate becomes higher in the elderly. ${ }^{60-64}$ DN B cells have recently emerged in many inflammatory and aging diseases, particularly in autoimmune disorders. For example, $\mathrm{CD}^{-} 7^{-} \mathrm{IgD}^{-} \mathrm{B}$ cell proportion correlates with the clinical manifestations, ${ }^{65,66}$ and upregulation of autoantibodies of SLE patients. ${ }^{65,67}$ Mechanistically, $\mathrm{CD}^{-} \mathrm{IgD}^{-} \mathrm{B}$ cells are able to become plasmablasts and plasma cells and subsequently secrete autoantibodies. $^{66,68}$ Our current study shows that $\mathrm{CD} 27^{-}$ $\mathrm{IgD}^{-} \mathrm{DN} \mathrm{B}$ cells are increased and positively correlated with glaucomatous visual field loss, indicative of a pathogenic role of this $B$ cell subset.

Although future in-depth studies are urgently needed to address issues such as the roles of different $B$ cell subsets in glaucoma, how $\mathrm{CD}_{2} 7^{-} \mathrm{IgD}^{-} \mathrm{B}$ cells contribute to the 

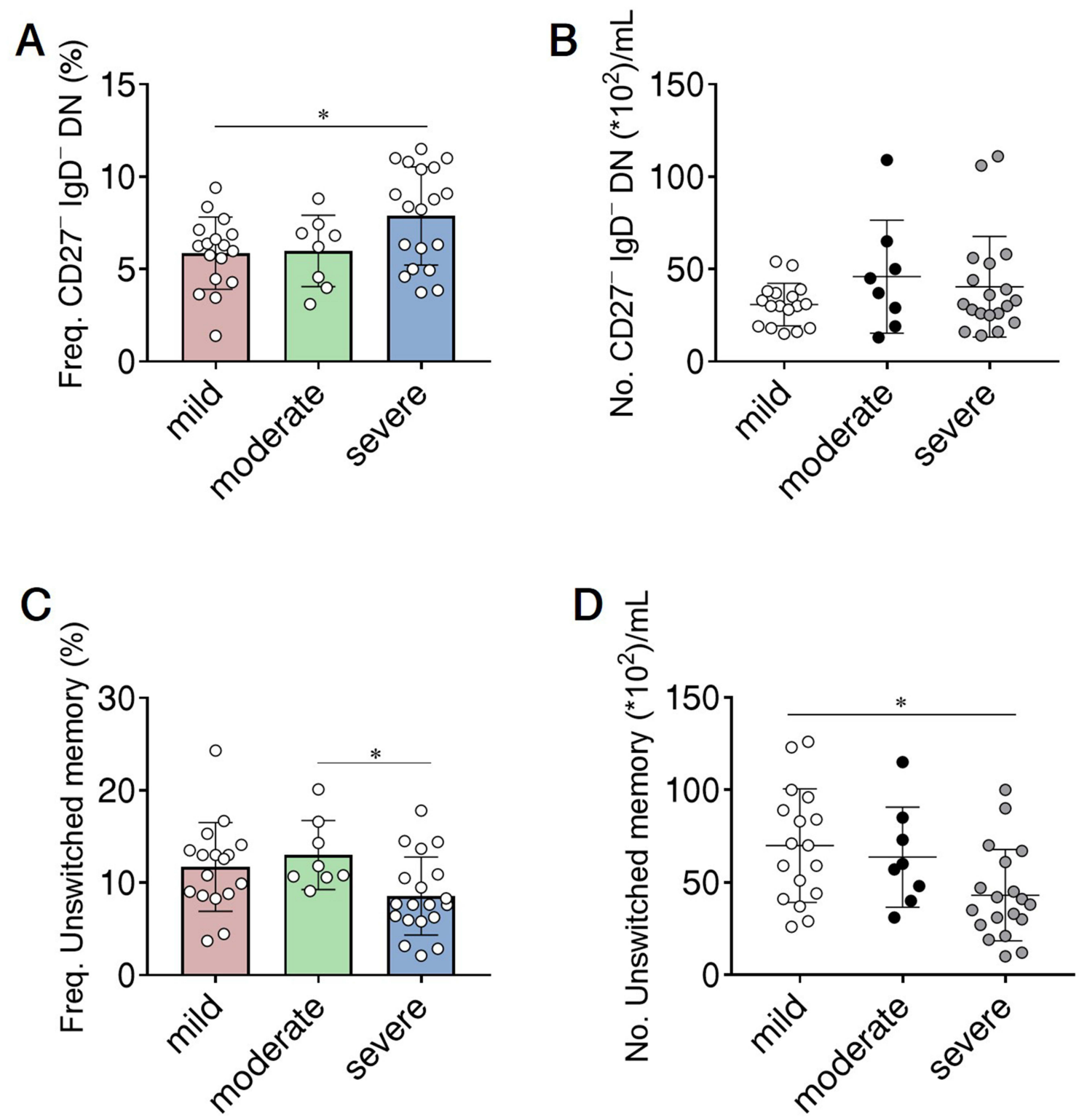

Figure 5 B cell subsets correlate with the clinical severity of glaucoma. The severity of glaucoma was determined based on the mean deviation (MD) of visual field: mild indicates visual field MD of greater than $-6 d B(n=17)$; moderate, $-12 d B$ to $-6 d B(n=8)$; and severe, no greater than $-12 d B(n=19)$. The frequency and absolute number of (A and B) $C D 27^{-} \operatorname{lgD}{ }^{-} \mathrm{DN}$ and $(\mathbf{C}$ and $\mathbf{D})$ unswitched memory subpopulations in 3 clinical categories of glaucoma patients. *p $<0.0167$, one-way analysis of variance (ANOVA) was applied followed by Bonferroni Correction. The data are represented as means \pm SD.

pathogenesis, and how their differentiation and function are regulated, our study reveals the clinical severity of glaucoma is accompanied by alterations in the B cell subsets, and the correlation between B cell subsets and glaucoma severity suggests that they might be able to serve as potential biomarkers to monitor the disease progression.

\section{Abbreviations}

MGC, microglial cells; IL, interleukin; TNF, tumour necrosis factor; PBS, phosphate buffered saline; RGC, retinal ganglion cells; ON, optic nerve; NTG, normal tension glaucoma; PACG, primary angle-closure glaucoma; POAG, primary open-angle glaucoma; ASC, antibody-secreting cells; IOP, intraocular pressure; DN, double negative; MD, mean deviation; PBMC, peripheral blood mononuclear cells; HD, healthy donors; Ig, immunoglobulin; BSA, bovine serum albumin; SD, standard deviation.

\section{Ethics Approval}

The study was conducted in accordance with the Declaration of Helsinki and approved by the Institutional Review Board for Clinical Research of the Daping 
Hospital (No. 202192), and Sichuan Provincial People's Hospital (No. 201968). All subjects were well informed about the study and potential risk and signed an informed consent before participation.

\section{Funding}

This work is financially supported by grants from the National Natural Science Foundation of China (U19A2004, 81970803, 82070985) and Foundation of Sichuan Science and Technology Department (2019JDTD0014, 2021JDJQ0044).

\section{Disclosure}

The authors declare no competing interests.

\section{References}

1. Xie H, Li L, Zhu G, et al. Correction: infiltrated pre-adipocytes increase prostate cancer metastasis via modulation of the miR-301a/ androgen receptor (AR)/TGF- $\beta 1 / \mathrm{Smad} / \mathrm{MMP} 9$ signals. Oncotarget. 2016;7:83829-83830. doi:10.18632/oncotarget.13913

2. Tham YC, Li X, Wong TY, et al. Global prevalence of glaucoma and projections of glaucoma burden through 2040: a systematic review and meta-analysis. Ophthalmology. 2014;121:2081-2090. doi:10.1016/j.ophtha.2014.05.013

3. Kass MA, Heuer DK, Higginbotham EJ, et al. The Ocular Hypertension Treatment Study: a randomized trial determines that topical ocular hypotensive medication delays or prevents the onset of primary open-angle glaucoma. Arch Ophthalmol. 2002;120:701-713; discussion 829-730. doi:10.1001/archopht.120.6.701

4. Lichter PR, Musch DC, Gillespie BW, et al. Interim clinical outcomes in the Collaborative Initial Glaucoma Treatment Study comparing initial treatment randomized to medications or surgery. Ophthalmology. 2001;108:1943-1953. doi:10.1016/S0161-6420(01) 00873-9

5. Heijl A, Leske MC, Bengtsson B, et al. Reduction of intraocular pressure and glaucoma progression: results from the Early Manifest Glaucoma Trial. Arch Ophthalmol. 2002;120:1268-1279. doi:10.1001/archopht.120.10.1268

6. Adornetto A, Russo R, Parisi V. Neuroinflammation as a target for glaucoma therapy. Neural Regen Res. 2019;14:391-394. doi:10.4103/ 1673-5374.245465

7. Bell K, Und Hohenstein-Blaul NVT, Teister J, Grus F. Modulation of the immune system for the treatment of glaucoma. Curr Neuropharmacol. 2018;16:942-958. doi:10.2174/ 1570159X15666170720094529

8. Yanagi M, Kawasaki R, Wang JJ, et al. Vascular risk factors in glaucoma: a review. Clin Exp Ophthalmol. 2011;39:252-258. doi:10.1111/j.1442-9071.2010.02455.x

9. Marcus MW, de Vries MM, Junoy Montolio FG, Jansonius NM. Myopia as a risk factor for open-angle glaucoma: a systematic review and meta-analysis. Ophthalmology. 2011;118:1989-1994 e1982. doi:10.1016/j.ophtha.2011.03.012

10. Shen L, Melles RB, Metlapally R, et al. The association of refractive error with glaucoma in a multiethnic population. Ophthalmology. 2016;123:92-101. doi:10.1016/j.ophtha.2015.07.002

11. Tezel G, Yang X, Luo C, et al. Oxidative stress and the regulation of complement activation in human glaucoma. Invest Ophthalmol Vis Sci. 2010;51:5071-5082. doi:10.1167/iovs.10-5289
12. Williams PA, Marsh-Armstrong N, Howell GR, et al. Neuroinflammation in glaucoma: a new opportunity. Exp Eye Res. 2017;157:20-27. doi:10.1016/j.exer.2017.02.014

13. Ramirez AI, de Hoz R, Salobrar-Garcia E, et al. The role of microglia in retinal neurodegeneration: Alzheimer's disease, Parkinson, and glaucoma. Front Aging Neurosci. 2017;9:214.

14. Jiang S, Kametani M, Chen DF. Adaptive immunity: new aspects of pathogenesis underlying neurodegeneration in glaucoma and optic neuropathy. Front Immunol. 2020;11:65. doi:10.3389/ fimmu.2020.00065

15. Gramlich OW, Ding QJ, Zhu W, et al. Adoptive transfer of immune cells from glaucomatous mice provokes retinal ganglion cell loss in recipients. Acta Neuropathol Commun. 2015;3:56. doi:10.1186/ s40478-015-0234-y

16. Wax MB, Barrett DA, Pestronk A. Increased incidence of paraproteinemia and autoantibodies in patients with normal-pressure glaucoma. Am J Ophthalmol. 1994;117:561-568. doi:10.1016/ S0002-9394(14)70059-5

17. Wax MB, Tezel G, Saito I, et al. Anti-Ro/SS-a positivity and heat shock protein antibodies in patients with normal-pressure glaucoma. Am J Ophthalmol. 1998;125:145-157. doi:10.1016/S0002-9394(99) 80084-1

18. Wax MB, Tezel G, Kawase K, Kitazawa Y. Serum autoantibodies to heat shock proteins in glaucoma patients from Japan and the United States. Ophthalmology. 2001;108:296-302. doi:10.1016/S01616420(00)00525-X

19. Rizzo MI, Greco A, De Virgilio A, et al. Glaucoma: recent advances in the involvement of autoimmunity. Immunol Res. 2017;65:207-217. doi:10.1007/s12026-016-8837-3

20. Joachim SC, Bruns K, Lackner KJ, Pfeiffer N, Grus FH. Antibodies to alpha B-crystallin, vimentin, and heat shock protein 70 in aqueous humor of patients with normal tension glaucoma and IgG antibody patterns against retinal antigen in aqueous humor. Curr Eye Res. 2007;32:501-509. doi:10.1080/02713680701375183

21. Grus FH, Joachim SC, Bruns K, et al. Serum autoantibodies to alpha-fodrin are present in glaucoma patients from Germany and the United States. Invest Ophthalmol Vis Sci. 2006;47:968-976. doi:10.1167/iovs.05-0685

22. Joachim SC, Reichelt J, Berneiser S, Pfeiffer N, Grus FH. Sera of glaucoma patients show autoantibodies against myelin basic protein and complex autoantibody profiles against human optic nerve antigens. Graefes Arch Clin Exp Ophthalmol. 2008;246:573-580. doi:10.1007/s00417-007-0737-8

23. Tezel G, Seigel GM, Wax MB. Autoantibodies to small heat shock proteins in glaucoma. Invest Ophthalmol Vis Sci. 1998;39:2277-2287.

24. Wax MB, Tezel G, Edward PD. Clinical and ocular histopathological findings in a patient with normal-pressure glaucoma. Arch Ophthalmol. 1998;116:993-1001. doi:10.1001/archopht.116.8.993

25. Gramlich OW, Beck S, von Thun Und Hohenstein-blaul N, et al. Enhanced insight into the autoimmune component of glaucoma: igG autoantibody accumulation and pro-inflammatory conditions in human glaucomatous retina. PLoS One. 2013;8:e57557. doi:10.1371/journal. pone. 0057557

26. Wax MB, Tezel G, Yang J, et al. Induced autoimmunity to heat shock proteins elicits glaucomatous loss of retinal ganglion cell neurons via activated T-cell-derived fas-ligand. $J$ Neurosci. 2008;28:12085-12096. doi:10.1523/JNEUROSCI.3200-08.2008

27. Joachim SC, Grus FH, Kraft D, et al. Complex antibody profile changes in an experimental autoimmune glaucoma animal model. Invest Ophthalmol Vis Sci. 2009;50:4734-4742. doi:10.1167/iovs.08-3144

28. Joachim SC, Wax MB, Seidel P, Pfeiffer N, Grus FH. Enhanced characterization of serum autoantibody reactivity following HSP 60 immunization in a rat model of experimental autoimmune glaucoma. Curr Eye Res. 2010;35:900-908. doi:10.3109/02713683.2010.495829 
29. Joachim SC, Gramlich OW, Laspas P, et al. Retinal ganglion cell loss is accompanied by antibody depositions and increased levels of microglia after immunization with retinal antigens. PLoS One. 2012;7:e40616. doi:10.1371/journal.pone.0040616

30. Laspas P, Gramlich OW, Müller HD, et al. Autoreactive antibodies and loss of retinal ganglion cells in rats induced by immunization with ocular antigens. Invest Ophthalmol Vis Sci. 2011;52:8835-8848. doi:10.1167/iovs.10-6889

31. Noristani R, Kuehn S, Stute G, et al. Retinal and optic nerve damage is associated with early glial responses in an experimental autoimmune glaucoma model. $J$ Mol Neurosci. 2016;58:470-482. doi:10.1007/s12031-015-0707-2

32. Bell K, Wilding C, Funke S, Pfeiffer N, Grus FH. Protective effect of 14-3-3 antibodies on stressed neuroretinal cells via the mitochondrial apoptosis pathway. BMC Ophthalmol. 2015;15:64. doi:10.1186/ s12886-015-0044-9

33. Wilding $\mathrm{C}$, Bell $\mathrm{K}$, Beck $\mathrm{S}$, et al. $\gamma$-Synuclein antibodies have neuroprotective potential on neuroretinal cells via proteins of the mitochondrial apoptosis pathway. PLoS One. 2014;9:e90737. doi:10.1371/journal.pone.0090737

34. Chen CL, Bojikian KD, Wen JC, et al. Peripapillary retinal nerve fiber layer vascular microcirculation in eyes with glaucoma and single-hemifield visual field loss. JAMA Ophthalmol. 2017;135:461-468. doi:10.1001/jamaophthalmol.2017.0261

35. He C, Shi Y, Wu R, et al. miR-301a promotes intestinal mucosal inflammation through induction of IL-17A and TNF-alpha in IBD. Gut. 2016;65:1938-1950. doi:10.1136/gutjnl-2015-309389

36. Forestier A, Guerrier T, Jouvray M, et al. Altered B lymphocyte homeostasis and functions in systemic sclerosis. Autoimmun Rev. 2018;17:244-255. doi:10.1016/j.autrev.2017.10.015

37. Klein U, Rajewsky K, Kuppers R. Human immunoglobulin (Ig)M $+\mathrm{IgD}+$ peripheral blood B cells expressing the CD27 cell surface antigen carry somatically mutated variable region genes: CD27 as a general marker for somatically mutated (memory) B cells. $J$ Exp Med. 1998;188:1679-1689. doi:10.1084/jem.188.9.1679

38. Li S, Ma F, Hao H, et al. Marked elevation of circulating CD19(+) CD38(hi)CD24(hi) transitional B cells give protection against neonatal sepsis. Pediatr Neonatol. 2018;59:296-304. doi:10.1016/j. pedneo.2017.10.005

39. Piper CJM, Wilkinson MGL, Deakin CT, et al. CD19(+)CD24(hi) CD38(hi) B cells are expanded in juvenile dermatomyositis and exhibit a pro-inflammatory phenotype after activation through toll-like receptor 7 and interferon-alpha. Front Immunol. 2018;9:1372. doi:10.3389/fimmu.2018.01372

40. Sambleben C, Knudsen AD, Hartling HJ, Nielsen CH, Nielsen SD. Increased proportions of $\mathrm{B}$ cells with spontaneous production of interleukin-10 in HIV-infected individuals are normalized during combination antiretroviral therapy: a longitudinal study. APMIS 2018;126:143-151. doi:10.1111/apm.12795

41. Giltiay NV, Giordano D, Clark EA. The plasticity of newly formed B cells. $\quad J$ Immunol. 2019;203:3095-3104. doi:10.4049 jimmunol.1900928

42. Sosa-Hernandez VA, Torres-Ruíz J, Cervantes-Díaz R, et al. B cell subsets as severity-associated signatures in COVID-19 patients. Front Immunol. 2020;11:611004. doi:10.3389/fimmu.2020.611004

43. Oliviero B, Varchetta S, Mele D, et al. Expansion of atypical memory B cells is a prominent feature of COVID-19. Cell Mol Immunol. 2020;17:1101-1103. doi:10.1038/s41423-020-00542-2

44. De Biasi S, Lo Tartaro D, Meschiari M, et al. Expansion of plasmablasts and loss of memory $\mathrm{B}$ cells in peripheral blood from COVID-19 patients with pneumonia. Eur $J$ Immunol. 2020;50:1283-1294. doi:10.1002/eji.202048838

45. Anderson MG, Libby RT, Gould DB, Smith RS, John SW. High-dose radiation with bone marrow transfer prevents neurodegeneration in an inherited glaucoma. Proc Natl Acad Sci U S A. 2005;102:4566-4571. doi:10.1073/pnas.0407357102
46. Chen H, Cho K-S, Vu THK, et al. Commensal microflora-induced $\mathrm{T}$ cell responses mediate progressive neurodegeneration in glaucoma. Nat Commun. 2018;9:3209. doi:10.1038/s41467-018-05681-9

47. Yang X, Zeng Q, Göktas E, et al. T-lymphocyte subset distribution and activity in patients with glaucoma. Invest Ophthalmol Vis Sci. 2019;60:877-888. doi:10.1167/iovs.18-26129

48. Yu H, Yuan L, Yang Y, et al. Increased serum IgA concentration and plasmablast frequency in patients with age-related macular degeneration. Immunobiology. 2016;221:650-656. doi:10.1016/j. imbio.2016.01.004

49. Kalinina Ayuso V, van Dijk MR, de Boer JH. Infiltration of plasma cells in the iris of children with ANA-positive anterior uveitis. Invest Ophthalmol Vis Sci. 2015;56:6770-6778. doi:10.1167/iovs.15-17351

50. Wang RX, Yu C-R, Dambuza IM, et al. Interleukin-35 induces regulatory $\mathrm{B}$ cells that suppress autoimmune disease. Nat Med. 2014;20:633-641. doi:10.1038/nm.3554

51. Abu El-Asrar AM, Dheyab A, Khatib D, Struyf S, Van Damme J, Opdenakker G. Efficacy of B cell depletion therapy with rituximab in refractory chronic recurrent uveitis associated with Vogt-KoyanagiHarada disease. Ocul Immunol Inflamm. 2020;1-8. doi:10.1080/ 09273948.2020.1820531

52. Miserocchi E, Modorati G, Berchicci L, et al. Long-term treatment with rituximab in severe juvenile idiopathic arthritis-associated uveitis. Br J Ophthalmol. 2016;100:782-786. doi:10.1136/bjophthalmol-2015-306790

53. Wiendl M, Becker E, Müller TM, et al. Targeting immune cell trafficking - insights from research models and implications for future IBD therapy. Front Immunol. 2021;12:656452. doi:10.3389/ fimmu.2021.656452

54. Polman CH, O'Connor PW, Havrdova E, et al. A randomized, placebo-controlled trial of natalizumab for relapsing multiple sclerosis. $N$ Engl $J$ Med. 2006;354:899-910. doi:10.1056/ NEJMoa044397

55. Kappos L, Antel J, Comi G, et al. Oral fingolimod (FTY720) for relapsing multiple sclerosis. $N$ Engl J Med. 2006;355:1124-1140. doi:10.1056/NEJMoa052643

56. Maurer D, Fischer GF, Fae I, et al. IgM and IgG but not cytokine secretion is restricted to the CD27+ B lymphocyte subset. $J$ Immunol. 1992;148:3700-3705.

57. Agematsu K, Hokibara S, Nagumo H, Komiyama A. CD27: a memory B-cell marker. Immunol Today. 2000;21:204-206. doi:10.1016/S0167-5699(00)01605-4

58. Liu YJ, de Bouteiller O, Arpin C, et al. Normal human IgD+IgMgerminal center B cells can express up to 80 mutations in the variable region of their IgD transcripts. Immunity. 1996;4:603-613. doi:10.1016/S1074-7613(00)80486-0

59. Klein U, Kuppers R, Rajewsky K. Human IgM+IgD+ B cells, the major B cell subset in the peripheral blood, express $\mathrm{V}$ kappa genes with no or little somatic mutation throughout life. Eur J Immunol. 1993;23:3272-3277. doi:10.1002/eji.1830231232

60. Claes N, Fraussen J, Vanheusden M, et al. Age-associated B cells with proinflammatory characteristics are expanded in a proportion of multiple sclerosis patients. J Immunol. 2016;197:4576-4583. doi:10.4049/jimmunol.1502448

61. Colonna-Romano G, Bulati M, Aquino A, et al. A double-negative (IgD-CD27-) B cell population is increased in the peripheral blood of elderly people. Mech Ageing Dev. 2009;130:681-690. doi:10.1016/j. mad.2009.08.003

62. Fraussen J, Marquez S, Takata K, et al. Phenotypic and Ig repertoire analyses indicate a common origin of $\mathrm{IgD}-\mathrm{CD} 27-$ double negative $\mathrm{B}$ cells in healthy individuals and multiple sclerosis patients. J Immunol. 2019;203:1650-1664. doi:10.4049/jimmunol.1801236

63. Wu YC, Kipling D, Dunn-Walters DK. The relationship between CD27 negative and positive B cell populations in human peripheral blood. Front Immunol. 2011;2:81. doi:10.3389/fimmu.2011.00081 
64. Bulati M, Buffa S, Candore G, et al. B cells and immunosenescence: a focus on IgG+IgD-CD27- (DN) B cells in aged humans. Ageing Res Rev. 2011;10:274-284. doi:10.1016/j.arr.2010.12.002

65. Wei C, Anolik J, Cappione A, et al. A new population of cells lacking expression of CD27 represents a notable component of the B cell memory compartment in systemic lupus erythematosus. $J$ Immunol. 2007;178:6624-6633. doi:10.4049/jimmunol.178.10.6624

66. Jenks SA, Cashman KS, Zumaquero E, et al. Distinct effector B cells induced by unregulated toll-like receptor 7 contribute to pathogenic responses in systemic lupus erythematosus. Immunity. 2018;49:725739 e726. doi:10.1016/j.immuni.2018.08.015
67. Richardson C, Chida AS, Adlowitz D, et al. Molecular basis of 9G4 B cell autoreactivity in human systemic lupus erythematosus. J Immunol. 2013;191:4926-4939. doi:10.4049/jimmunol.1202263

68. You X, Zhang R, Shao M, et al. Double negative B cell is associated with renal impairment in systemic lupus erythematosus and acts as a marker for nephritis remission. Front Med (Lausanne). 2020;7:85. doi: $10.3389 /$ fmed.2020.00085

\section{Publish your work in this journal}

The Journal of Inflammation Research is an international, peerreviewed open-access journal that welcomes laboratory and clinical findings on the molecular basis, cell biology and pharmacology of inflammation including original research, reviews, symposium reports, hypothesis formation and commentaries on: acute/chronic inflammation; mediators of inflammation; cellular processes; molecular mechanisms; pharmacology and novel anti-inflammatory drugs; clinical conditions involving inflammation. The manuscript management system is completely online and includes a very quick and fair peerreview system. Visit http://www.dovepress.com/testimonials.php to read real quotes from published authors. 